Article

\title{
Transport and Carbon Emissions in the United States: The Long View
}

\section{Lee Schipper $^{1, *}$, Calanit Saenger ${ }^{2}$ and Anant Sudardshan ${ }^{3}$}

1 Global Metropolitan Studies, University of California, Berkeley / 1950 Addison St., Suite 202, Berkeley, CA 94720, USA

2 Agricultural and Resource Economics, University of California, Berkeley / 207 Giannini Hall, Berkeley, CA 94720, USA; E-Mail: calanit@berkeley.edu

3 Precourt Energy Efficiency Center, Stanford University, Stanford, CA 94305, USA;

E-Mail: anants@stanford.edu

* Author to whom correspondence should be addressed; E-Mail: schipper@berkeley.edu; Tel.: +1-510-642-6889; Fax: +1-510-642-6061.

Received: 31 January 2011; in revised form: 23 February 2011 / Accepted: 16 March 2011/ Published: 24 March 2011

\begin{abstract}
The following analysis traces U.S. transport $\mathrm{CO}_{2}$ emissions in combustion by mode for 1960-2008. Changes in emissions are divided into components related to overall population and economic growth, transport mode shift, changes in the ratio of fuel used to passenger or tonne-km of activity, and changes in the $\mathrm{CO}_{2}$ content of fuels. Where data permit we show how changes in vehicle utilization affected $\mathrm{CO}_{2}$ emissions. We comment on factors causing the changes in components of emissions. A Log-Mean Divisia Index and Laspeyres decompositions of the 1960-2008 changes are calculated. From this decomposition we speculate to what extent the factors associated with the increases in $\mathrm{CO}_{2}$ emissions since 1960 would be important in the future, and what other factors could reduce emissions. This thorough decomposition is imperative for the crafting of transport policy that aims to address climate change.
\end{abstract}

Keywords: U.S. transport; $\mathrm{CO}_{2}$ emissions; fuel intensity 


\section{Introduction: Evolution of Carbon Emissions from Domestic Transport Activities}

The transportation sector has become the leading and most-rapidly growing contributor to GHG emissions in the U.S. as well as globally. In 2007, the transportation sector was responsible for a third of U.S. GHG emissions from $\mathrm{CO}_{2}$ and $28 \%$ of global $\mathrm{GHG}$ emissions [1]. $\mathrm{CO}_{2}$ emissions from the U.S. transportation sector exceed total $\mathrm{CO}_{2}$ emissions of any other economy in the world besides China [1].

The sector's almost total reliance of petroleum fuels [2] is a major determinant of this trend. Other major contributors are urban development patterns, higher incomes and generally low fuel prices, that led to an increase of vehicle ownership as well as increase of Vehicle miles traveled (VMT) [3]. Between 1960 and 2008, highway travel has grown threefold due to higher population, greater number of vehicles per capita, and higher vehicle use per vehicle [4].

Driven largely by rising economic activity, transport emissions have more than tripled since 1960, augmenting the need to include transportation in climate regulation. While attention has been largely directed to reducing vehicles' emissions per kilometer and reducing the $\mathrm{CO}_{2}$ content of fuels, other important factors were overlooked. Understanding the underlying forces responsible for the increased demand for passenger transport (henceforth "travel") and freight over the long-run yields important insights into additional ways transport policies may moderate carbon emissions. With recent high-level commissions pointing to the need for significant reform in transport financing and policy [5], understanding the links between vehicle activity and $\mathrm{CO}_{2}$ will assist crafting policies that effectively address transport emissions. This paper contributes to the global discussion over the urgency to reduce $\mathrm{CO}_{2}$ emissions by 2050 to 1990 levels, by analyzing transport emissions pathways between 1960 and 2008.

The following analysis begins with a review of past major trends in transport activity and emissions. We continue with presenting a useful decomposition framework and comment on the prospects of future regulation to address the issues brought up by our findings.

\section{Results and Discussion}

\subsection{Data}

Energy use by mode is created using data from the Oak Ridge Transportation Energy Data Book [2] and the online National Transportation Statistics from the Bureau of Transport Statistics [4]. The share of light trucks used as household vehicles follows key surveys [6,7] and estimates published by [4] and [5]. Travel data are from [7] and [8]. Freight hauled by medium trucks and light trucks is estimated at 3 tonnes and $200 \mathrm{~kg}$ per vehicle $\mathrm{km}$, respectively in order to include this vehicle activity. Using standard $\mathrm{CO}_{2}$ coefficients, these fuel consumption data are converted into $\mathrm{CO}_{2}$ emissions from fuel combustion in vehicles [5]. The small amount of electricity used for rail systems is converted to primary energy and $\mathrm{CO}_{2}$ emissions at U.S. averages for the year in question.

This work is carried out in S.I. units. The reader should recall that a Quad (quadrillion British thermal units, a common U.S. unit, $\left.10^{15} \mathrm{BTU}\right)$ is approximately 1.055 exajoules $\left(10^{18} \mathrm{Joules}\right)$ and a BTU/passenger-mile is approximately 1.7 megajoules (mJ)/passenger-kilometer. 10 liters $/ 100 \mathrm{~km}$ of consumption of gasoline is equal to 23.65 miles per gallon. 


\subsection{Historical Trends}

Between 1960 and 2008, travel volume (in passenger-km) grew by a factor of nearly 3.5, while freight grew almost 3 times, as reflected in Figures 1 and 2, respectively. While travel has been dominated by cars and personal light trucks or SUVs, providing 90\% of travel in 1960, air travel actually grew faster and went from under $3 \%$ to over $12 \%$ of total travel by 2008 . Rail and bus shares tumbled from just over 7\% in 1960 to around 4\% in 2008. Similarly for freight, the share of trucks rose to almost $32 \%$ of tonne-km by 2008 , while rail fell from $36 \%$ of freight in 1960 to $33 \%$ in 2008 . The share of water-borne freight decreased significantly while air freight, although under $1 \%$ in 2008 of total freight travel, grew ten-fold over the entire 48 year period. Notably, the modes of travel and freight that consume the most energy per unit of service grew faster than those that use the least energy.

Figure 1. Total Passenger Travel by mode.

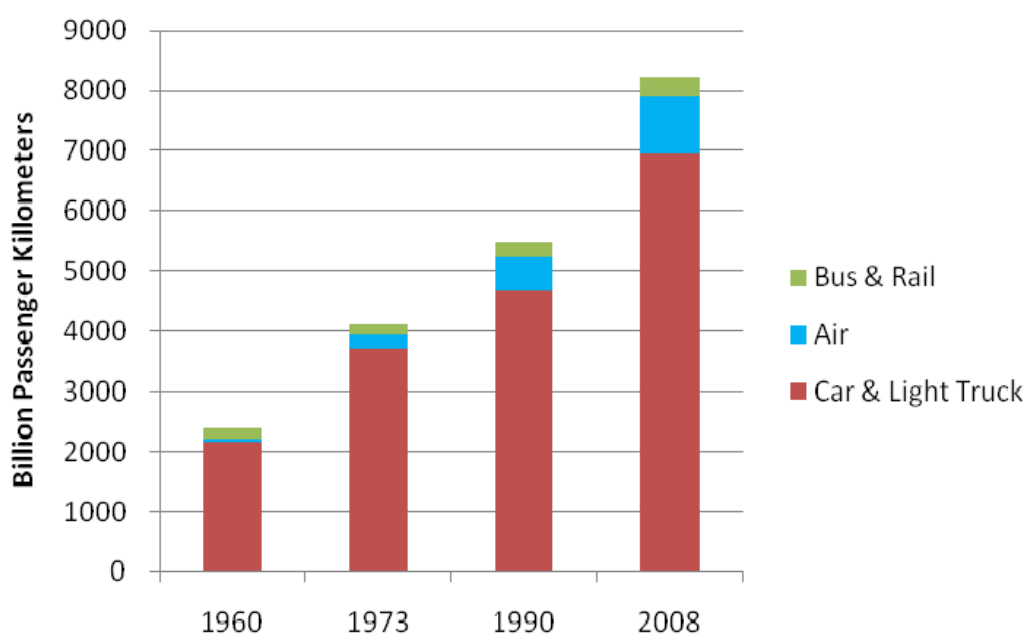

Figure 2. Total Freight Travel by mode.

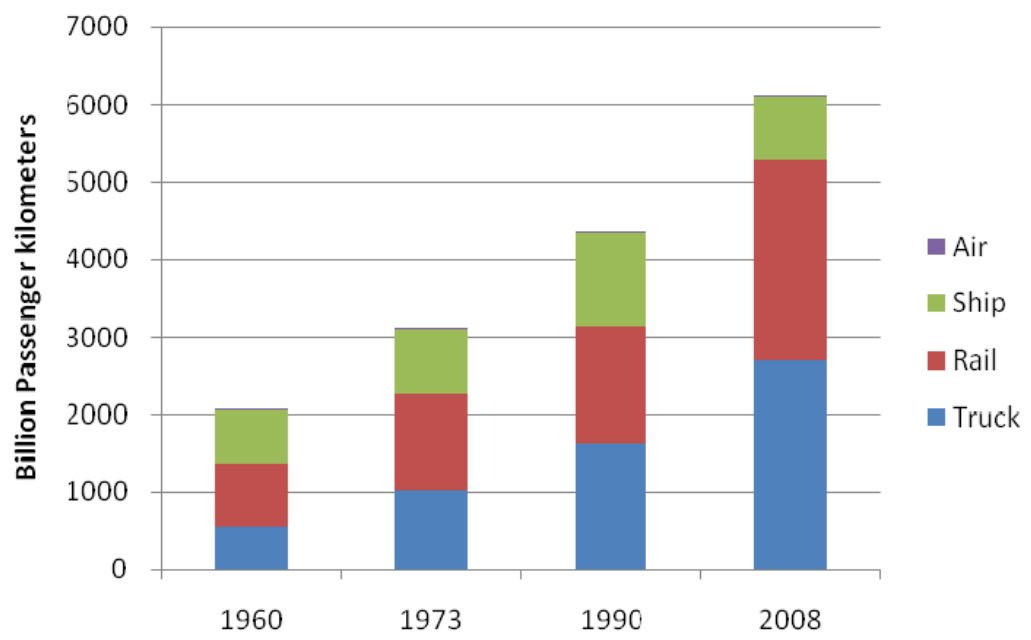


Figures 3 and 4 show the respective total $\mathrm{CO}_{2}$ emissions by each mode in the same four benchmark years. Not surprisingly, cars and air travel, and truck freight dominate carbon increases, both because these modes dominate transport activity and because they generally have the highest emission per passenger- or tonne-kilometer.

Figure 3. Passenger Travel Carbon emissions.

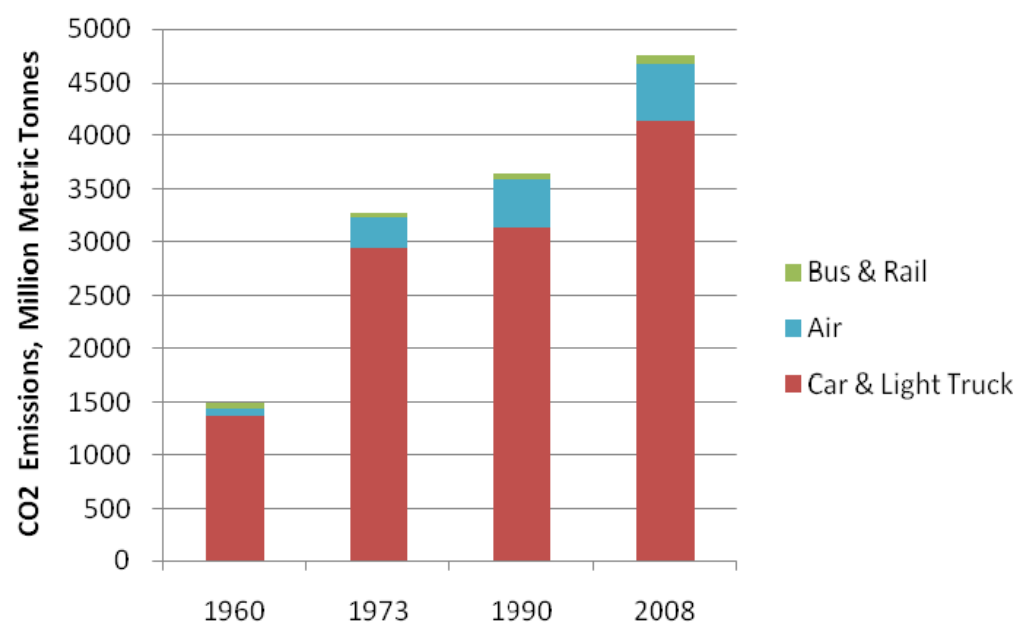

Figure 4. Freight Carbon Emissions.

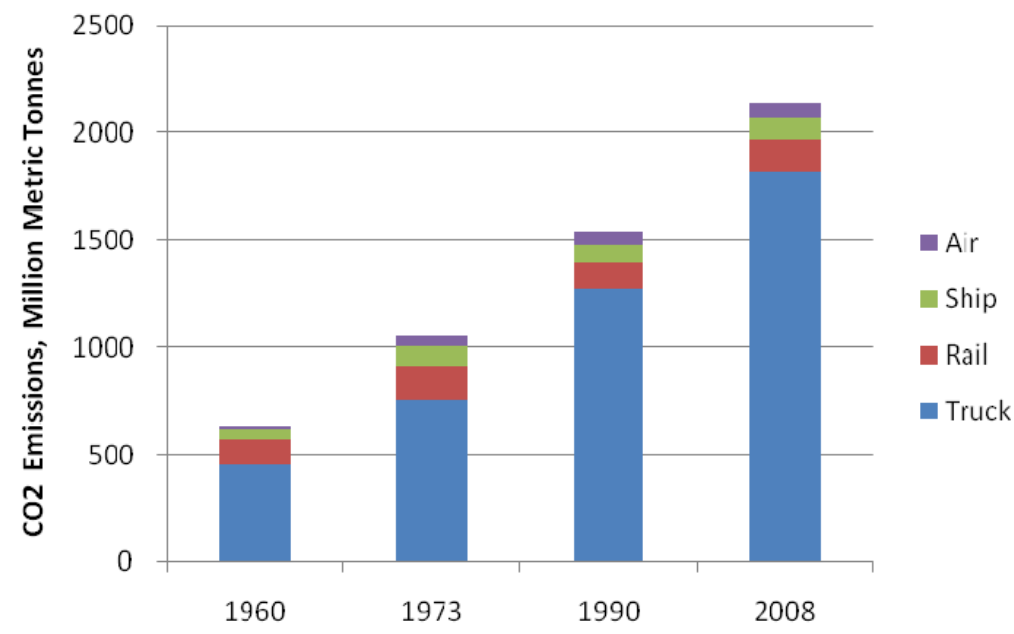

To understand whether an economy is becoming more or less $\mathrm{CO}_{2}$ intensive it is useful to compare the trends in transport to trends in GDP. While GDP is not necessarily a perfect measure, the amount of passenger travel certainly depends on people's wealth, just as the amount of freight moved is related to overall economic activity. Significantly, neither travel nor freight rose as rapidly as GDP throughout the entire period, although travel led by cars did outpace GDP from 1960 to 1973 but diverged from GDP growth by almost 1\%/year, in the years after. The ratio of tonne-km of freight to GDP fell by almost 1\%/year from 1960 to 2008. [9] Relative to GDP, emission grew less rapidly, suggesting a loosening of the coupling of energy use and emissions from economic growth.

Figures 5 (for travel) and 6 (for freight) summarize the aggregate changes, where 1973 serves as the base year. Per capita travel and freight increased in all periods (travel/capita) but GDP grew faster, so the GDP intensity of domestic travel or freight fell (travel/GDP). Aggregate emissions per unit of 
travel fell after 1973, but that of freight rose to a plateau in the 1990s (emissions/unit of travel). When emissions intensities are normalized to GDP, they demonstrate a steady decline from 1970 (travel emissions/GDP).

Figure 5. Summary of Emissions Changes from Passenger Travel.

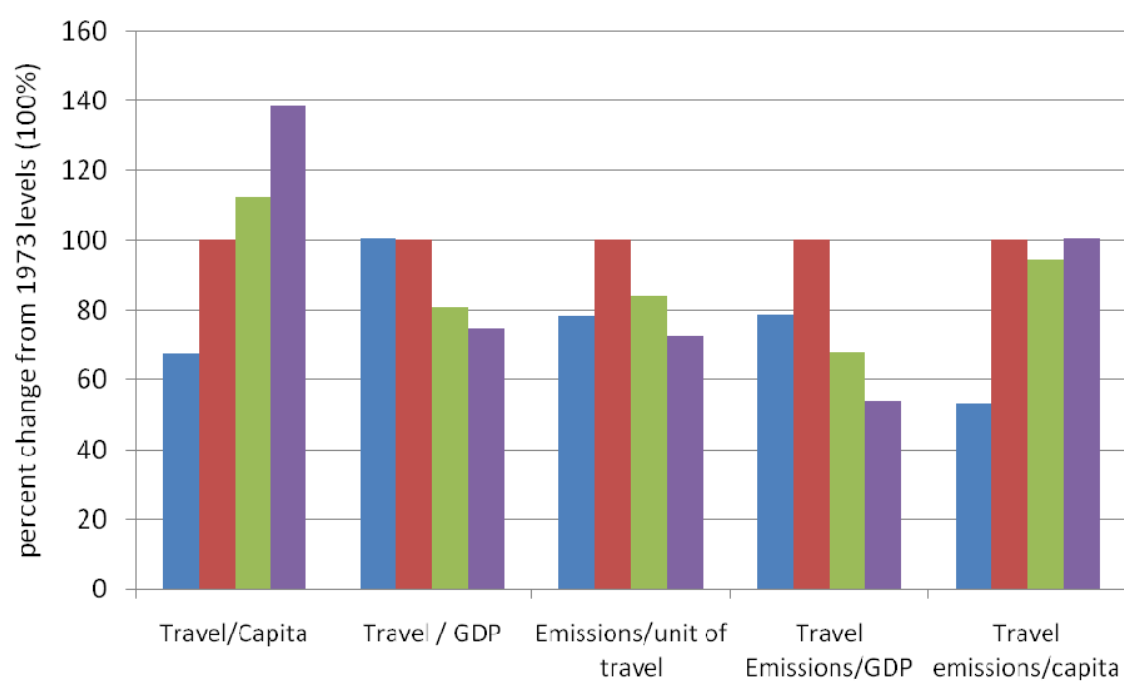

$\square 1960 \quad 1973 \quad \square 1990 \quad \square 2008$

Figure 6. Summary of Emissions Changes from Freight.

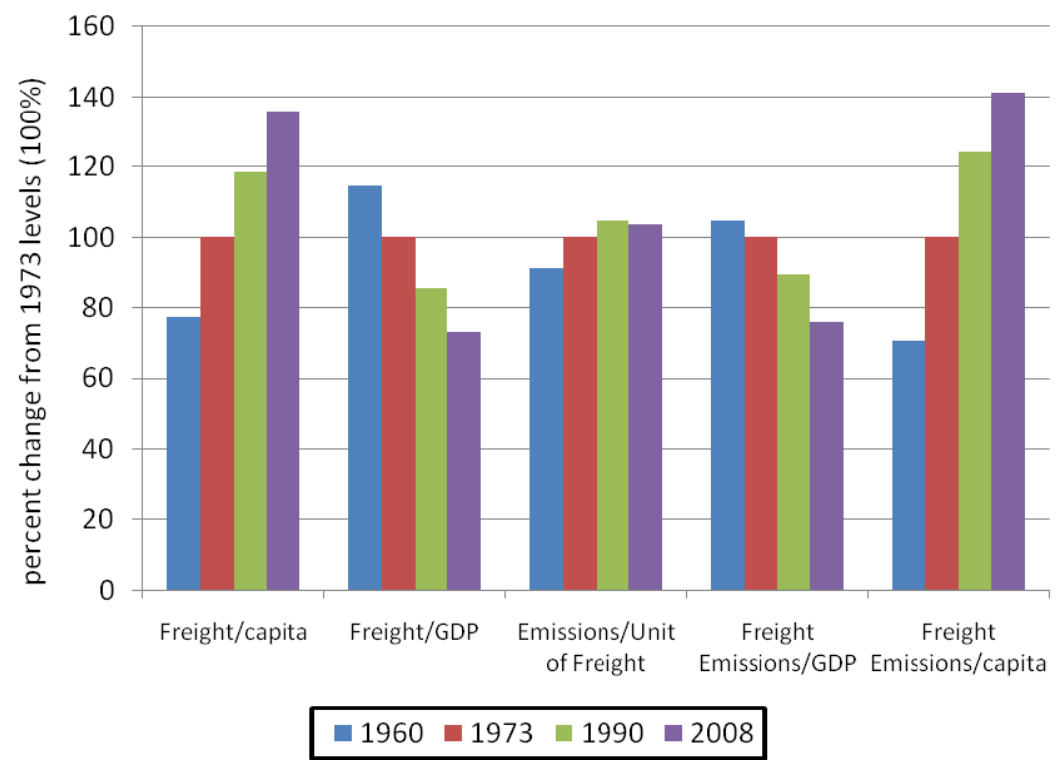

Consequently, as compared with GDP, the U.S. economy became less travel and freight intensive over time. Some of the drop in travel and certainly the drop in freight were enabled by foreign mobility substituting for domestic, as imports have been increasing. While per capita emissions from travel or freight were higher in the late 2000s than in the earlier years shown, decreasing carbon intensities contributed to the dramatic shrinking of emissions to GDP. Since travel emissions/GDP fell more than freight emissions/GDP, the share of freight in total transport emissions increased, a fact often overlooked by many observers. 


\section{Carbon Intensities Pathways}

A modal carbon intensity is defined in this analysis as the ratio of carbon emissions (Figures 3 and 4) to passenger for travel or tonne-kilometers for freight (Figures 1 and 2). This section follows the changes in intensities over the discussed period and describes the structural changes that explain them.

\subsection{Passenger Travel}

For cars and light trucks, a meaningful vehicle carbon intensity (in grams of carbon dioxide per vehicle-km), can be calculated, which is related to the inverse of fuel economy of each kind of vehicle. Figure 7 compares the resulting $\mathrm{CO}_{2}$ intensities of each mode of passenger travel. From 1973 to 2008 major reductions in carbon intensity occurred in air travel (55\% fewer emissions per passenger kilometer), and car travel (33\% less emissions per vehicle kilometer and 15\% fewer emissions per passenger kilometer).

Figure 7. Carbon Intensities of Travel by Mode.

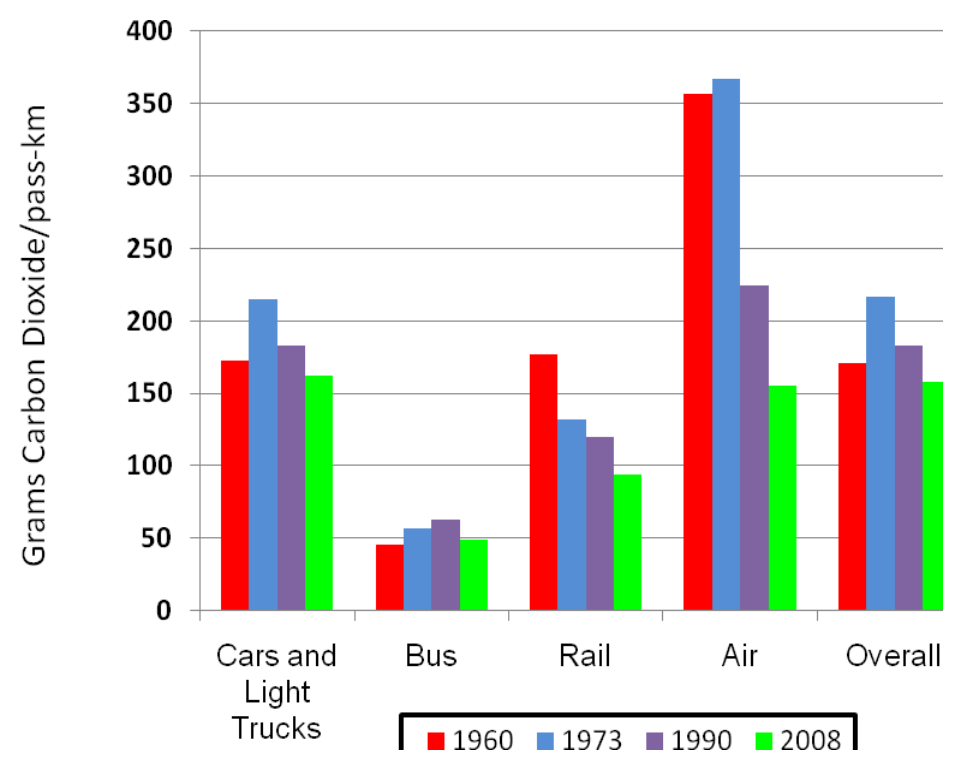

Automobile fuel economy improvements associated with lower carbon intensity of vehicle use were largely in response to national fuel economy standards and higher fuel prices. Apportioning the size of these two forces has been a subject of much debate [10-12]. New cars sold after 1973 initially became much lighter and less powerful, but gradually their engines were more efficient [13]. Indeed, a new car or light truck sold in 2007 used half as much energy per unit of weight in tests as one sold in the 1970s. Since new car weight had crept back up to $80 \%$ of the 1975 values for cars, and above 1975 values for light trucks, the decline in test fuel used per kilometer of new cars and light trucks sold compared to those sold in 1973 was closer to $33 \%$ at its maximum in the late 1990s. Consequently, by 2007, this change had worked its way through the entire stock of cars and light trucks (excluding commercial vans and pickups). The average household's light duty vehicle on the road used 33\% less fuel $/ \mathrm{km}$ and emitted correspondingly less $\mathrm{CO}_{2}$ than one in 1973 [14].

The drop in light duty vehicle occupancy is an important factor that offsets some of the reduction in fuel use per vehicle-kilometer. Defined as the average number of people per vehicle over all kilometers 
driven, vehicle occupancy fell from over 2 in 1969 [8] toslightly over 1.5 by 2001 [15]. The decline meant that roughly $1 / 3$ more vehicle kilometers were driven to provide a given number of passenger-kilometers than in 1969. Thus emissions/passenger-km fell significantly less than emissions/veh-km. The long-term trend of a drop in vehicle occupancy occurred as auto ownership increased, and more households sent two commuters with their own cars to work. Some of this decline occurred as fewer Americans made trips by other modes and instead drove alone. Additionally, American household size fell from close to 3.4 in 1960 to about 2.6 after 2000. With fewer children and many more single person households, there were fewer people sharing rides.

Changes in fuel prices have to be given some credit for changes in transportation fuel use. Figure 8 shows the real price of gasoline in the U.S. since 1960, the real price of $1 \mathrm{~km}$ worth of gasoline, and the share of household expenditures on gasoline as given in the annual consumer expenditure survey. Not surprising is that improved fuel economy helped keep the cost of fuel $/ \mathrm{km}$ down. Surprisingly, fuel

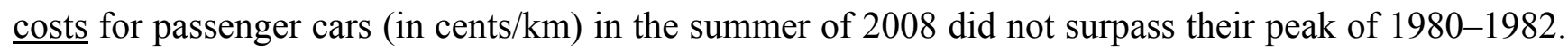
Yet in the same year, transit ridership was back at its 1957 absolute level [16], and according to preliminary information from the Federal Highway Administration, in 2008 the total of all vkt fell $3.6 \%$ from its 2007 value [17]. Unfortunately full data on utilization of cars and other modes in 2008 were not collected in the National Household Travel Survey, but the emerging picture shows less car use and a continued slight shift to transit.

Figure 8. Changes in real and relative road fuel prices, 1960-2009.

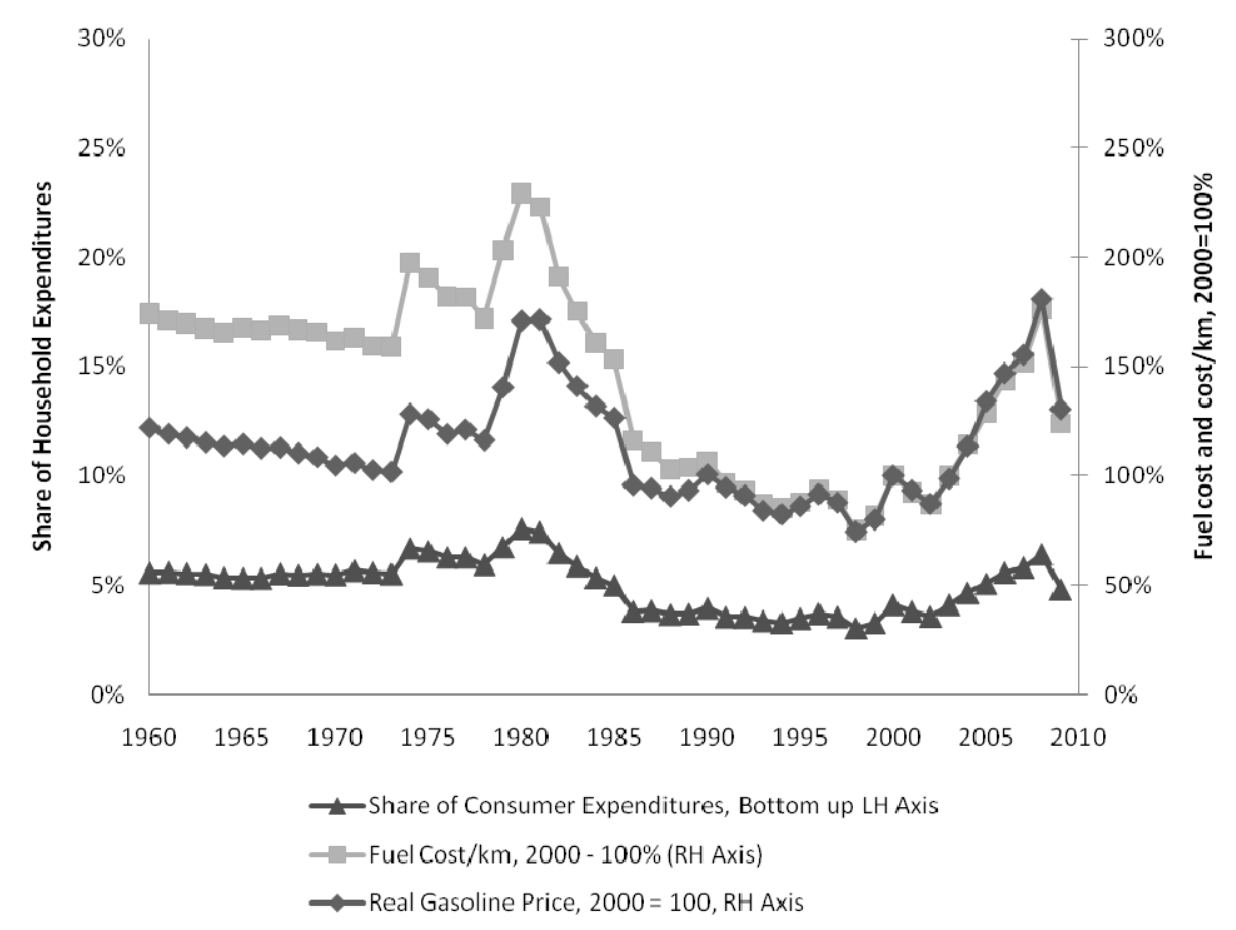

Calculating the same kind of changes for air travel, available data [4] show that the real price of jet fuel went from $\$ 1 /$ gallon to $\$ 2.44$ /gallon (real 2,000 \$) between 1980 and 2008, while the fuel used per passenger $\mathrm{km}$ fell almost $46 \%$, leaving the fuel cost per passenger-km $25 \%$ higher in 2008 than in 1980. For trucking, the increase in diesel fuel costs has been significantly greater than the decline in fuel use/tonne-km, leaving trucking paying about $20 \%$ more per tonne-km in 2007 than in 1980 for 
diesel fuel. Ironically, it is households who saw the least pressure from fuel prices, relatively, except for a few months in 2008 when gasoline rose well above \$4/gallon in nominal terms.

While automobile fuel use was reshaped by efficiency standards, there were no similar policies aimed at air travel. Instead, technological progress permits aircraft today to carry more passengers on two engines than they carried on four in 1973 [4]. In terms of air travel, many non-stop flights between smaller cities were eliminated because of unprofitability, particularly after decontrol, in favor of hub-and-spoke patterns developed by the major airlines [18], which contributed to higher load factors. In addition, air travel intensity fell because the capacity utilization of airplanes increased substantially, with planes at about $80 \%$ full in 2006 compared with around $50 \%$ in the early 1970s [4]. While this meant aircraft became more crowded, the impact on reducing fuel consumption was large. The resulting decline in the energy or carbon intensity of air travel of $60 \%$ between 1973 and 2006 was the largest among any major transportation mode.

Rail passenger traffic, which includes commuter rail and intercity rail as well as metros in large cities, was affected by various restructuring activities. Some intercity passenger rail lines had very low energy intensities, such as those well utilized lines in the North East corridor or major commuter lines. In all Amtrak's energy intensity (including the primary energy for electricity) was well below that of auto or air travel. With commuter rail, light rail, and metros, the overall intensity of this mode was also well under that of the automobile, even counting the primary equivalent of electricity used to power many passenger lines.

Bus travel, which includes intercity buses, school buses, and urban buses, had a mixed record. For parts of the 1990s, the average city bus released more $\mathrm{CO}_{2}$ per passenger-km than the average car/light truck because buses had so few passengers. But by 2000 a new generation of buses used progressively less fuel $/ \mathrm{km}$, so that with an average of 9 passengers/bus, intensity fell below that of automobiles again. Intercity buses and school buses had lower energy intensities so that the overall energy or carbon intensity of bus travel was lower than that of car travel throughout the entire period [19].

\subsection{Freight Transport}

For freight, as Figure 9 shows, there was an increase in the intensity of trucking (in carbon dioxide emissions/tonne-km) in the $1970 \mathrm{~s}$ and $1980 \mathrm{~s}$ of $5.5 \%$ and then a decline of $14 \%$ between 1990 and 2008. In rail freight there was a steady decrease of intensity from the 1970 s, while a small increase in water-borne freight intensity can be observed. Air freight, not shown here because it is well off the scale, demonstrated a steady decline consistent with that for travel, hitting a value of around $200 \mathrm{gm} /$ tonne-km in 2008.

Although carbon intensity of trucking in 1990 was slightly above its 1973 level, intensities in 2008 were below those of 1973. Improved engines, tires, lower friction and streamlining of truck cabs and tractors permitted reductions in fuel use per vehicle kilometer for a given size truck [20,21]. Major policy shifts in trucking also changed past practices. With deregulation of interstate trucking in the late 1970s, haulers were permitted to return home loaded, not empty, permitting more freight hauled per kilometer driven and thus driving down carbon intensity of truck freight for a given truck.

Rail freight went through a number of reorganizations and emerged strong in the 1990s with both large bulk shipments (grains, ores, fuels, cars, etc.) as well as trailer on flat car deliveries across the 
country. As with trucking, the increase in average payload with some modest improvements in diesel engine reduced the energy required and carbon emitted to haul a tonne a kilometer by 2006 to slightly under half of its value in the early 1970s. This last point is important, because vehicle size/capacity and degree of capacity utilization explain more of the variations in carbon intensity over time (as well as cross-sectional differences among countries) than engine efficiencies per se [20,22].

Figure 9. Carbon Intensities of Freight, by Mode.

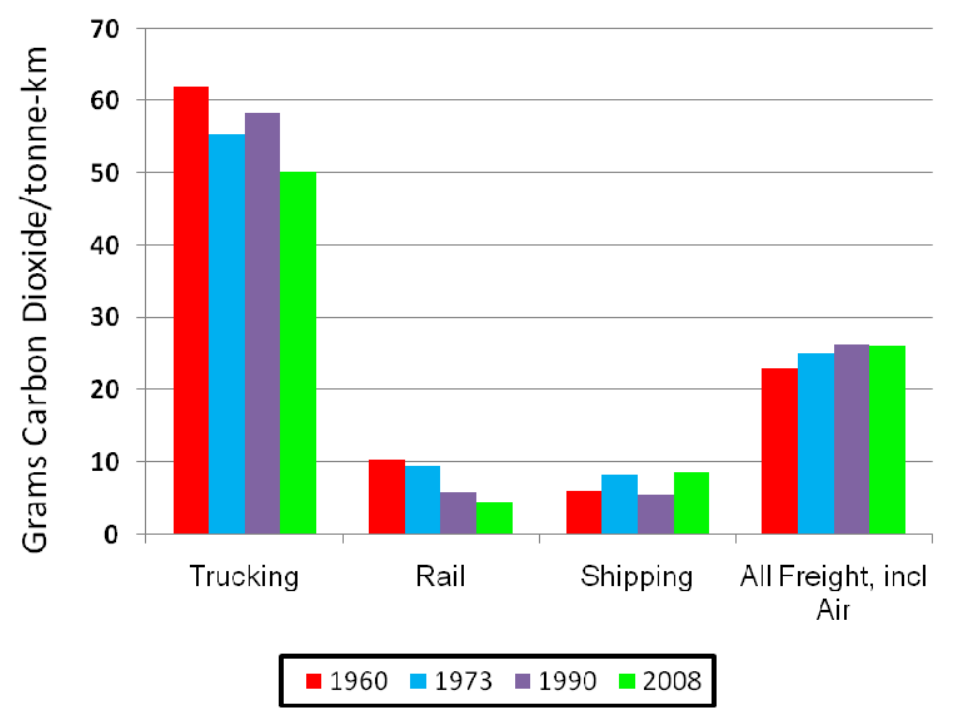

Technological improvements to vehicles, improved transport industry management practices in response to competition, changing fuel prices, and influential national policy all contributed to the general trend of decreasing carbon intensities in all transportation modes. That emissions rose less rapidly than transport activities after 1973 is not surprising. For most of the period since 1973, U.S. energy policy focused on oil use in the transport sector, particularly the reduction of oil use per kilometer of car, truck, or aircraft movements. These forces reduced fuel intensities, which slowed the rise in emissions.

In spite of these reductions in carbon intensities, total emissions in 2008 were higher than they were in 1973 and are still growing, as can be seen in Figures 3 and 4. Per capita emissions for travel in 2008 were only marginally above their level of 1973, indicating that the changes in emission intensities for car and air travel almost offset the increases in per capita travel for these modes. For freight, however, per capita emissions have increased steadily despite lower intensities. Indeed, overall emissions from freight have risen faster than those from travel, similar to the trends observed in most developed countries [2].

To summarize, within each transport category, overall shifts towards the most energy and carbon intensive modes raised emissions, particularly for freight. At the same time, the most important modes became less carbon intensive. For travel, the decline in these emissions intensities was far more significant than the shift towards car and air travel. In freight, by contrast, the rise of trucking's share was significant enough to offset the drop in trucking and rail emissions intensities. Still, aggregate freight carbon intensity was slightly higher in 2008 than in 1990 and 4\% above its 1973 level, while that for travel was nearly $25 \%$ below its 1973 value. We explore a more detailed decomposition of these effects and differences below. 


\section{Decomposition of Overall Changes}

An important consideration for policymakers is the aggregate impact of changes over time. Policies that focus solely on carbon intensities of vehicles and not on systematic changes in travel volume and mode may overlook important shifts that offset or even overcome the savings from lower vehicle carbon intensities. For example, even though the intensity of trucking, the dominant component of both freight and transport emissions, declined from 1960 to 1973, the aggregate carbon intensity of freight actually increased. Because car travel, air travel and truck freight are the most carbon intensive modes, shifts in their relative importance can reinforce or offset changes in individual intensities. On the other hand, transport policies that take advantage of improvements in the travel or freight system that either raise vehicle utilization or promote shifts to less carbon intensive modes can give fuel and $\mathrm{CO}_{2}$ savings at no change in technology. To understand the overall effect on emissions that is reflected in mode shift, intensity shifts, change in fuel mix, and the overall level of travel or freight, we provide additional decomposition techniques. While the foregoing descriptive analysis reveals what lies behind aggregate changes, more powerful decomposition techniques yield greater insights about the past and the future [21].

The starting point of this decomposition is the ASIF equation, developed to understand and decompose components that multiply to yield a given output or input [23].

$$
\mathbf{G}(\text { Emissions })=\mathbf{A} \times \mathbf{S}_{k} \times \mathbf{I}_{k, j} \times \mathbf{F}_{k, j}
$$

A represents total transport activity in passenger-km (or tonne-km for freight), $\mathbf{S}$ is the modal shares (in $\%$ of total passenger or tonne-km carried by each mode $k$ ), $\mathbf{I}$ is the fuel intensity of each mode, in energy use per passenger (or tonne-) $\mathrm{km} k$ using fuel or energy source $j$, and $\mathbf{F}$ is the carbon content of each fuel $k$ used in mode $j$.

I depends both on the vehicle energy intensity, $\mathbf{V}$ (in energy per vehicle-km), and vehicle utilization, $\mathbf{L}$ in passengers or tonnes. I has two subscripts, one for mode $j$ (travel or freight) and one for fuel type $k$. This reflects the fact that the fuel intensities of vehicles, travel, or freight may be a function of the fuel itself.

$\mathbf{F}$ expresses the carbon content of a given fuel $k$ used for a given mode $j$. For simplicity it is assumed that fuels are fully combusted, so their carbon contents are given by the Intergovernmental Panel on Climate Change (IPCC). In more sophisticated formulations life-cycle analysis accounts for the $\mathrm{CO}_{2}$ released not only in combustion but in preparation of the fuel and for large transit systems construction of infrastructure [24]. This analysis does count the primary energy and emissions associated with electricity use for traction. For the U.S. this is small and essentially limited to some Amtrak and intercity and urban rail services and trolley buses, overall tiny compared to the diesel fuel used by buses and railroads.

With this formulation the decomposition asks how much changes in $\mathbf{A}, \mathbf{S}, \mathbf{I}$ and $\mathbf{F}$ combine to yield a change in $\mathbf{G}$ over time. Note that the "ASIF" identity summarizes at the most aggregate level how different components of carbon emissions have changed.

The simplest approach asks the question "how much did total emissions change over any period because of a change in a single factor from a given base year?" This "all else equal" technique is called a Laspeyres decomposition [25]. This approach is computationally simple but can leave large 
residuals - the product of each change does not yield the total change because of cross terms. A more sophisticated technique uses the Log Mean Divisia Index or LMDI [26]. This approach has the advantage of using a rolling baseline and allocating the cross terms that appear when all of the components of the ASIF identity have changed over time. Ang [26] argues that LMDI decomposition indices have significant advantages over other decomposition techniques [27]. However, LMDI is computationally challenging and in many cases simpler techniques such as the Laspeyres decomposition produce similar results.

In this paper we produce a set of indices using both techniques partly for comparative purposes. We use 1990 as a base year for the Laspeyres decomposition, as present $\mathrm{CO}_{2}$ negotiations use that same year for a base. Since LMDI does not have fixed weights, a base year is not necessary. Figures 10 and 11 present, at the end of this section, present the LMDI results for different years normalizing 1990 to 100 so that comparisons from that date may be easily made. Table 1 provides the same information in a little more detail. Each index in table one measures the overall change in emissions, owing to changes in an ASIF factor, with the 1990 levels fixed as 100\%. Where these indices are falling, changes in the corresponding factor can be understood as contributing to a decline in emissions.

Table 1. Decomposition of Changes in Carbon Emissions from Travel and Freight, 1960-2008.

\begin{tabular}{|c|c|c|c|c|c|c|c|c|}
\hline & \multicolumn{7}{|c|}{ LMDI Index } & \multirow{2}{*}{$\begin{array}{c}\text { Laspeyres } \\
1960-2008 \\
\end{array}$} \\
\hline & 1960 & 1970 & 1973 & 1980 & $1990=100 \%$ & 2008 & 1960-2008 & \\
\hline \multicolumn{9}{|l|}{ Travel } \\
\hline Actual & $43.17 \%$ & $76.58 \%$ & $89.57 \%$ & $87.99 \%$ & $100.0 \%$ & $126.49 \%$ & $310.72 \%$ & $317.8 \%$ \\
\hline Activity & $45.51 \%$ & $68.70 \%$ & $75.75 \%$ & $77.81 \%$ & $100.0 \%$ & $148.95 \%$ & $340.05 \%$ & $326.0 \%$ \\
\hline Mode Shift & $93.6 \%$ & $97.25 \%$ & $97.50 \%$ & $98.01 \%$ & $100.0 \%$ & $99.22 \%$ & $106.33 \%$ & $103.6 \%$ \\
\hline Vehicle Use & $83.78 \%$ & $81.83 \%$ & $85.65 \%$ & $93.89 \%$ & $100.0 \%$ & $95.17 \%$ & $113.94 \%$ & \multirow{2}{*}{$84.9 \%$} \\
\hline Fuel Intensity & $128.61 \%$ & $144.02 \%$ & $142.39 \%$ & $123.86 \%$ & $100.0 \%$ & $88.53 \%$ & $69.77 \%$ & \\
\hline Fuel Mix & $98.17 \%$ & $97.10 \%$ & $99.25 \%$ & $99.08 \%$ & $100.0 \%$ & $101.54 \%$ & $103.48 \%$ & $105.1 \%$ \\
\hline Carb. Content & $100 \%$ & $100 \%$ & $100 \%$ & $100 \%$ & $100 \%$ & $100 \%$ & $100 \%$ & \\
\hline \multicolumn{9}{|l|}{ Summary } \\
\hline Pkm/GDP & $117.1 \%$ & $128.9 \%$ & $123.5 \%$ & $106.79 \%$ & $100.0 \%$ & $88.4 \%$ & $75.5 \%$ & \\
\hline Emissions/GDP & $115.7 \%$ & $144.6 \%$ & $146.7 \%$ & $121.25 \%$ & $100.0 \%$ & $79.8 \%$ & $68.9 \%$ & \\
\hline \multicolumn{9}{|l|}{ FREIGHT } \\
\hline Actual & $43.56 \%$ & $57.40 \%$ & $68.30 \%$ & $82.05 \%$ & $100.0 \%$ & $130.50 \%$ & $302.24 \%$ & $335.3 \%$ \\
\hline Activity & $51.21 \%$ & $67.04 \%$ & $74.11 \%$ & $91.17 \%$ & $100.0 \%$ & $130.54 \%$ & $264.90 \%$ & $295.6 \%$ \\
\hline Mode Shares & $78.63 \%$ & $84.38 \%$ & $89.93 \%$ & $86.38 \%$ & $100.0 \%$ & $109.71 \%$ & $142.13 \%$ & $142.7 \%$ \\
\hline Fuel Intensity & $113.43 \%$ & $107.27 \%$ & $107.86 \%$ & 109.25 & $100.0 \%$ & $84.99 \%$ & $72.26 \%$ & $79.9 \%$ \\
\hline Fuel Mix & $95.29 \%$ & $94.72 \%$ & $95.13 \%$ & $95.49 \%$ & $100.0 \%$ & $107.17 \%$ & $111.21 \%$ & $103.4 \%$ \\
\hline Carbon Content & $100.0 \%$ & $100.0 \%$ & $100.0 \%$ & $100.0 \%$ & $100.0 \%$ & $100.0 \%$ & $100.0 \%$ & \\
\hline \multicolumn{9}{|l|}{ Summary } \\
\hline Tonne-km/GDP & $134.9 \%$ & $121.4 \%$ & $118.1 \%$ & $122.53 \%$ & $100.0 \%$ & $85.8 \%$ & $64.8 \%$ & \\
\hline Emissions/GDP & $117.1 \%$ & $108.23 \%$ & $111.9 \%$ & $113.06 \%$ & $100.0 \%$ & $85.2 \%$ & $72.7 \%$ & \\
\hline
\end{tabular}

Table 1 also compares the overall change from 1960 to 2008 for both Laspeyres and LMDI methods. As is evident they are quite similar. Note that for the passenger sector a simpler Laspeyres decomposition was used, merging the Vehicle Use $(\mathrm{Vkm} / \mathrm{Pkm})$ and Fuel Intensity (Energy/Vkm) 
indices. The relevant comparison here is of the product of the two LMDI indices (which yields an overall change of $79.70 \%$ ) with the Laspeyres estimate of $84.9 \%$. In general the comparison suggests that the much simpler Laspeyres decomposition can yield most of the qualitative conclusions we reach from the more involved LMDI technique. That said, for the remainder of this discussion we refer to LMDI decomposition outputs.

Figure 10. LMDI decomposition results for the passenger sector.

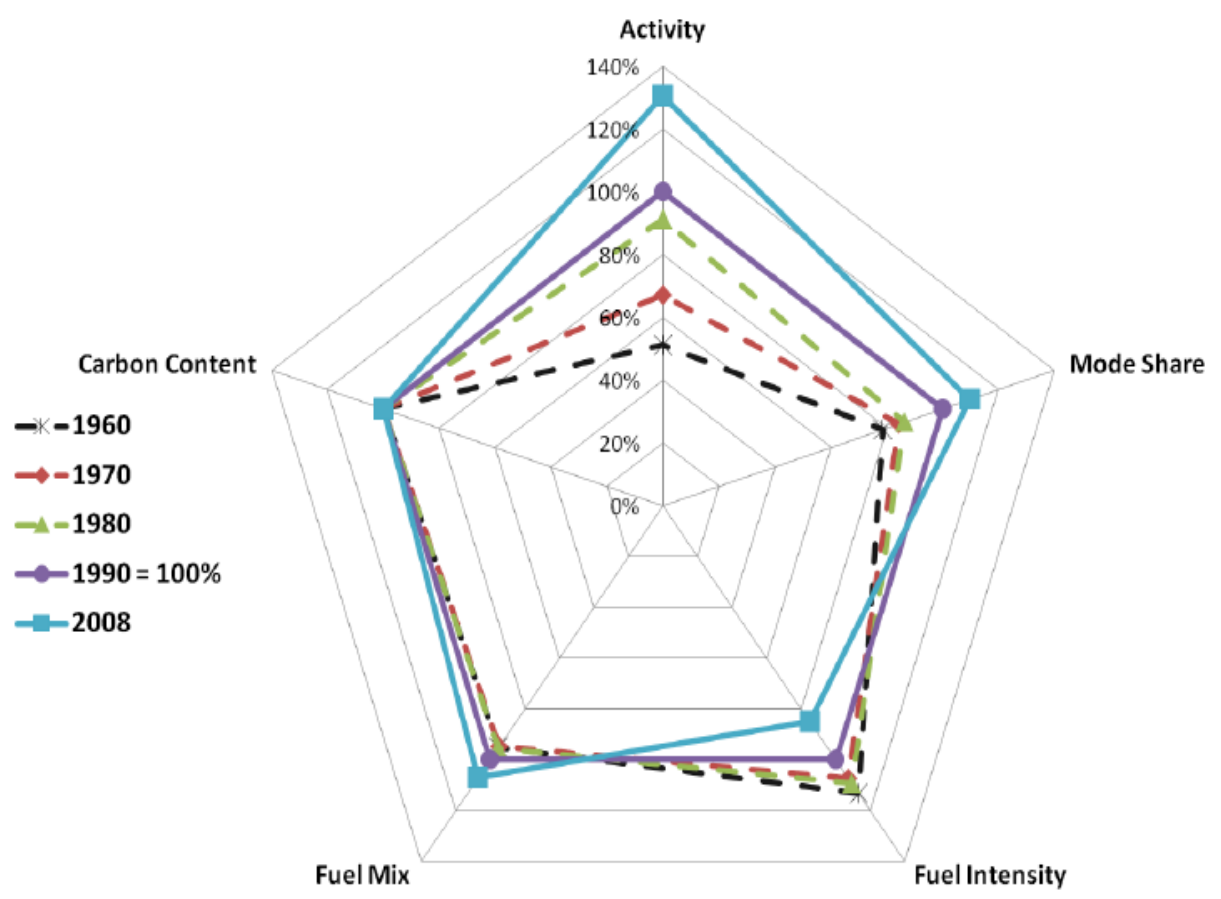

Figure 11. LMDI decomposition results for freight.

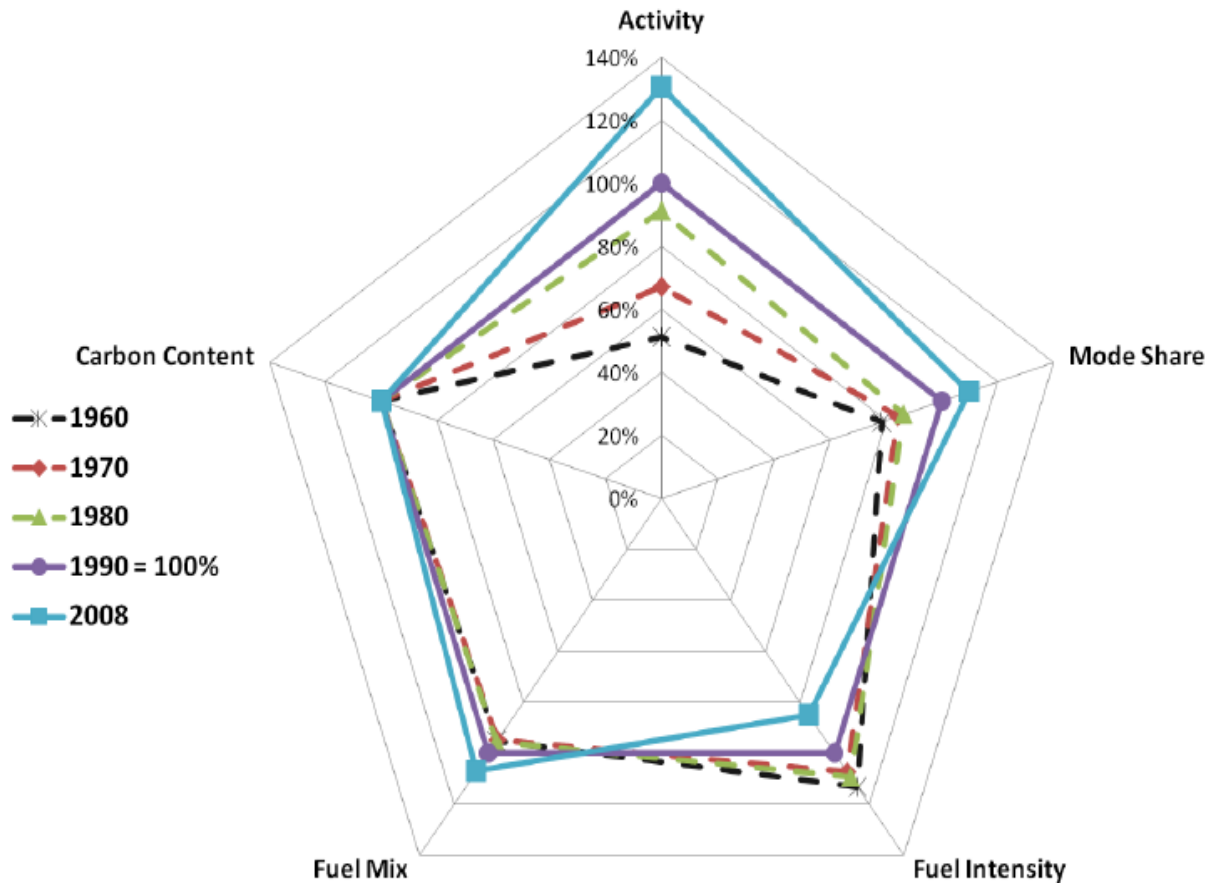


This decomposition technique can be used to project future trends [28], and reveal how much each of the multiplicative factors in ASIF formula can be altered away from their current trends to lead to lower $\mathrm{CO}_{2}$ emissions. Similarly, the approach supports a "back-casting" exercise whereby rough targets for emission in a future year can be compared to emissions levels today to scope out ranges of change in each of the formula's components that together might bring the U.S. from the present levels to proposed future levels.

Most obviously, the results in Table 1 show that overall emission levels increased due to higher travel volume. This is reflected in the "activity" term, which increased steadily from 1960, and continued rising through all four benchmark years, albeit significantly more slowly after 1990. This increase was strongly led by the increase in the absolute levels of car and then air travel. The same occurred in freight, with trucking leading much of the growth in overall freight. Travel and freight activity on each mode grew at different rates, giving rise to mode-shift within the sector as a whole, rather than simply shifts between the types of transport. However, the absolute levels of urban transit and intercity rail dropped for most of the period, indicating real shifts in modes from these to car or, for intercity rail, to air. These shifts raised emissions.

Overall the effect of the structural mode shifts within the passenger sector has been small (as observed in line 3). Transit and rail lost a small share to cars, but their share of travel in 1960 was so small that the impact of the shift on emissions was minor. Cars lost significant share to air travel, which now accounts for some $11 \%$ of all passenger km Americans travel at home. But by 1990, the base year in the calculation above, the intensity of flying was close to that of car travel, so that shift had only a small impact.

For freight the impact of mode shifts has been much larger. Trucking is much more fuel and $\mathrm{CO}_{2}$ intensive than rail or ship (Figure 6) and its share rose significantly, from around $25 \%$ of all tonne-kilometers hauled in 1960 to almost $45 \%$ by 2008. This accounts for the 1960 "mode share" index lying at less than $79 \%$ of its 1990 value in 1960 . The implied increase to 1990 continued almost unabated through 2008, when the mode share index reached $110 \%$ of its 1990 value. One reason for the big mode shift 1990-2008 was a near collapse of water-borne freight, whose overall level fell by nearly 33\% from its 1990 level. This was largely due to the fall in oil shipments from Alaska to mainland USA with the decline in oil production there. The volume of freight decreased relative to GDP, but not quite as rapidly as that of travel, and the overall emission relative to GDP for freight fell less than did freight volume.

To some degree the increase in emissions attributed to activity and mode shifts has been offset by improvements in both fuel intensity and the intensity of vehicle utilization. In the passenger sector, fuel intensity indices went from over $128 \%$ of 1990 values in 1960 to less than $89 \%$ by 2008 . This index measures the energy used per vehicle $\mathrm{km}$ traveled and is therefore closely linked to the technological energy efficiency of passenger transport. At the same time vehicle utilization rose from about $84 \%$ of its 1990 value in 1960 through the early 1990s until beginning to fall to about $95 \%$ of the 1990 value in 2008. Vehicle utilization is indicated by the inverse of the ratio of passenger kilometers to vehicle kilometers. The decline in index values in recent years was caused by an increase in the number of passengers sharing vehicles (principally air, urban rail and bus), as well as an end to the longer-term decline in vehicle occupancy of cars. Overall, this meant lower emissions for the same number of 
passenger kilometers. That is, if more people use the same number of vehicles, emissions fall compared to constant utilization, hence the value of the index falls.

For freight as well, efficiencies have improved as indicated by the intensity index going from over $113 \%$ of the 1990 value in 1960 to about $85 \%$ in 2008 . The intensity indicator here captures the effects on emissions of changes in energy used per tonne $\mathrm{km}$ in the freight sector.

Shifts in fuels had little impact on carbon intensities in the passenger sector. This is seen by the fact that the fuel mix index varies from $98.17 \%$ of 1990 values in 1960 to $101.54 \%$ in 2008 . The small impact arises because oil products—gasoline, diesel, jet fuel and marine or rail diesel—dominate. All release similar amounts of $\mathrm{CO}_{2}$ when burned relative to the energy they contain. Perhaps in the future were fuel shifts to electricity increase (and be accompanied by an increase in renewable generation), we might see this factor playing a greater role.

For freight there is a slightly larger influence of fuel mix changes, with this index alone contributing to a slow increase in emissions over the last five decades (from about 95\% of the 1990 levels in 1960 to about $107 \%$ in 2008 ).

To summarize, although significant gains have been achieved in fuel intensity for both passenger travel and freight, it is not sufficient to offset the leading factor in that contributed to an overall increase in emissions, namely travel activity. In order to gain the bold reductions in emissions required, policies must address not only the fuel intensity of travel modes, but travel volume as well. Thus policies such as smart growth plans, pay-as-you drive insurance and congestion fees are increasingly more significant in addressing emissions from travel.

In Freight increases in emissions can be attributed to changes in mode shifts and fuel mix, on top of activity. As the importation of finished goods is on the rise as well as the transport of consumer package goods, fresh foods, and high value items like electronics, the increase in the use of trucking is likely to continue [29], maintaining the aforementioned trends. Transport reforms can address these trends by shifting some trucking fees to variable costs based on actual km driven and applying congestion pricing to encourage trucking firms to reduce distances per shipment or tonne-km.

While the ASIF decomposition provides a strong analysis tool to identify the necessary policies to address transport emissions, experience suggests that achieving such policies may be challenging. The next section further discusses the impact of past regulation in the context the ASIF formula.

\section{The Impact of Regulation}

The ASIF decomposition can shed light on the effectiveness of transport policies, by understanding what components regulation has addressed and what components have been neglected. A prevailing national policy approach is supply-side regulation, early on dominated by CAFÉ — Corporate Average Fuel Economy standards instituted by congress in 1975, and more recently characterized by biofuel production subsidies.

In the context of the ASIF formula, fuel economy standards affect vehicle energy intensity (I). The ASIF decomposition makes it apparent that the gains obtained through fuel economy standards can be largely offset by increases in travel volume (A) and modal share (S). In fact, since VKT per capita had increased almost forty percent over its 1973 level by 1990, and nearly sixty percent by 2007, and GDP per capita - a driver of both VKT and oil use — increased even more, the lack of growth in oil use per 
capita through 2008 is a sign that CAFE standards had a strong effect [11]. CAFÉ standards provoked producers to produce more fuel efficient cars than otherwise would be demanded in the market with short-term gasoline price swings. Despite the effectiveness of CAFÉ standards to slow the pace of rising emissions levels, regulating fuel efficiency is a necessary but an insufficient step to achieve actual reduction in emissions.

A more recent trend in national transport regulation is both supply-side and demand-side subsidies. On the supply-side, subsidies for biofuels and other fuel alternatives were provided with the justification of reducing carbon emissions. Whether biofuels provide any carbon savings is still a contested issue, but in terms of the ASIF decomposition, such policies affect the $\mathbf{F}$ component (carbon content), where $\mathbf{A}$ and $\mathbf{S}$ components remain the large drivers of change for aggregate fuel use and carbon emissions.

On the demand side, subsidies for hybrid purchases and "cash for clunkers" programs are examples of targeted policies that affect new vehicles fleet fuel efficiency (the I component of ASIF formula). But these programs achieve questionable relative gains for their high costs to the public.

A recent addition to policy discussions has been Feebates, or bonus/malus [30,31]. The idea was proposed many decades ago in California [30]. New vehicles emitting less than a certain balance point of emissions (which could be the "standard") receive a rebate on new purchase price, proportional to the amount by which they lie below the standard, while cars over that standard value are taxed on top of the price. The balance point can correspond to the sales-weighted standard or other value, and can be reduced over time. The steepness of the slope of taxation or rebate per gram $/ \mathrm{CO}_{2}$ can also be varied. Preliminary results from France [31] suggest a measurable effect. Since this program was introduced, new light duty vehicle $\mathrm{CO}_{2} / \mathrm{km}$ in France went from fourth lowest to lowest in EU, and many other countries have developed such programs recently [30]. The overall impact of such policy design will be seen as an acceleration of the decline in intensity (I) for car travel, assuming vehicle occupancy is constant.

A final point that is frequently overlooked but has tremendous impact on actual effectiveness of transport policy is the regulatory context in the U.S. in general and in transport in particular. The size and fragmentation of U.S. transport sector makes it particularly challenging to regulate. On the consumer level, millions of decision makers make daily choices that have a cumulative effect on global GHG emissions. Additionally, regional, state and federal governments share duties of taxing, funding and building transport infrastructure. Different agencies within each governing body are in charge of different components. For example, National Highway Traffic Safety Administration sets the CAFÉ standards, while Environmental Protection Agency has to set air pollution standards. 2010 marks the first year where these two agencies are cooperating to obtain complimenting fuel efficiency standards.

Since market supply in transportation is a relatively concentrated market (12 automobile producers supply nearly all cars sold [32]), most regulation has been targeted at production. But this phenomenon has not made legislation any easier, since automobile manufacturers have been using their political and economic influence to contest regulation in courts, leading to prolonged periods between actual regulation and implementation. A prevalent outcome of court litigation is the adoption of lenient rules that appease plaintiffs. A notable example in transportation is the provision CAFÉ credits for installation of vehicle safety features. The result of these political and structural challenges is apparent 
in the legislation that is finally adopted by Congress. Laws are often vague or specify goals without specifying the methods to obtain them, such as specifying a fuel efficiency standard by certain year without specifying the requirements from automobile makers. In addition, the actual laws that are adopted are those who are likely not to be contested by the public or strong market players, thus subsidies are much more prevalent than taxes, many times at the cost of efficiency.

Given these challenges, an important consideration is that according to [33], congestion and traffic accidents have greater social costs per mile in comparison to the costs of environmental externalities. Thus, future regulation that can effectively address congestion and traffic volume of all traffic modes, will have significant co-benefits on emissions as well. Currently, this may be the easier route to take in order to affect future carbon emissions in the U.S., since price signals are grossly absent from U.S. policy scene. Paradoxically, given the enormous weight put upon administrative and judicial rulings that take years to promulgate, price signals in the U.S. are even more significant if steady reduction in $\mathrm{CO}_{2}$ emissions is to be made.

\section{Conclusions}

The structure of U.S. transportation system has changed significantly since 1960 . The volume of people and goods moved has more than tripled, and the dominant modes providing that transport have largely become the most energy intensive ones. While individual modes, particularly air travel and rail freight have undergone large cuts in energy use per unit of activity, trucking and car travel also saw falling fuel and carbon intensities. However, the overall result of changes in transport activity is that emissions have more than tripled since 1960, driven largely by greater economic activity and higher car ownership. Emissions from travel increased 10\% less than travel volume, while emissions from freight went up greater than the volume of freight, a result of strong growth in energy and emissions-intensive trucking. Reductions in the energy intensities of light duty vehicle travel, truck and rail freight, and air travel, had saved roughly 1/3 of all energy used for travel and freight through 2008 compared to a counterfactual of constant energy intensities from 1973 onward. This savings of roughly 12 EJ or slightly under 6 million barrels per day compares well with the slightly under 10 million barrels per day of oil and natural gas liquids the U.S. produced in 2008.

The most recent U.S. Government (EIA) forecast for total carbon emission from transport using the National Energy modeling System (NEMS) shows almost no growth by 2030 over 2006 [34]. The reason is predominantly falling intensities of the key modes. But as the preceding analysis suggests, improvements in fuel intensity, may well be offset by trends in other components impacting carbon emissions. Significant emissions cuts, as proposed in U.S. and global climate resolutions, must translate to further declines in intensities and some combination of shifts back to less carbon intensive modes and slower increases in travel or freight.

In order to address aggregate impact of the transportation sector on carbon emissions, effective policy approach, as well as subsequent research, must address all the components of the ASIF formula. While setting new standards for carbon content through LFCS regulation adopted in California and strengthening CAFÉ standards, as was recently implemented by EPA and NHTSA, are significant policy tools, they are simply not enough to obtain the bold emissions reductions required by 2050 . To 
obtain such an overarching impact on emissions, a combination of policies that address total travel volume and the transition to more fuel intensive travel modes (trucking and air) is necessary.

\section{Acknowledgements}

Lee Schipper acknowledges the support of the World Resources Institute to Global Metropolitan studies in the preparation of the original of this paper and the project "Atlantic Energy Efficiency", funded by the European Commission to the University of California Berkeley for support in preparing the final version of this paper. Calanit Saenger thanks Meridith Fowlie for support from the Department of Agricultural and Resources Economics, UC Berkeley. Anant Sudarshan acknowledges support of the Precourt Energy Efficiency Center. Michael Hanemann provided useful comments to an early draft.

\section{References and Notes}

1. International Energy Agency. International Energy Statistics 2010. Available online: http://data.iea.org/IEASTORE/DEFAULT.ASP (accessed on 10 March 2011).

2. Davis, S.C.; Diegel S.L.; Boundy R.G. The Oak Ridge Transport Energy Data Book (TEDB), 28th ed.; Oak Ridge National Laboratory, U.S. Department of Energy: Oak Ridge, TN, USA, 2009.

3. Cambridge Systematics, Inc. Moving Cooler: Surface Transportation and Climate Change; Urban Land Institute: Washington, DC, USA, 2009.

4. U.S. Department of Transportation, Bureau of Transportation Statistics. National Transportation Statistics; U.S. Department of Transportation, Bureau of Transportation Statistics: Washington, DC, USA, 2008.

5. Bipartisan Policy Center. Performance Driven: A New Vision for U.S. Transportation Policy; Bipartisan Policy Center: Washington, DC, USA, 2009.

6. U.S. Census Bureau. Truck Inventory and Utilization Survey 1962-1992; Available online: http://www.census.gov/svsd/www/vius/products.html (accessed on 10 March 2011).

7. U.S.Census Bureau. Vehicle Inventory and Utilization Survey 1997 and 2002. Available online: http://www.census.gov/svsd/www/vius/products.html (accessed on 10 March 2011).

8. Federal Highway Administration. Nationwide Personal Transportation Survey (NPTS) for 1960, 1977, 1983, 1990 and 1995; Federal Highway Administration: Washington, DC, USA, 1999.

9. New data from the Bureau of Transport Statistics show that the absolute tonne-km of oil and natural gas sent by pipeline declined from 1980 to 2008, as did the share of these commodities in total freight. Thus the decline in tonne-km/GDP understates the rate at which the domestic economy became less freight-intensive.

10. Greene, D.L. CAFÉ or Price? An Analysis of the Effects of Federal Fuel Economy Regulations and Gasoline Price on New Car MPG, 1978-89. Energy J. 1990, 11, 3.

11. Greene, D.L. Why CAFÉ Worked. Energy Policy 1998, 26, 8.

12. Schipper, L. Moving Forward With Fuel Economy Standards. Access 2009, Spring, P11-P19.

13. EPA. Light-Duty Automotive Technology and Fuel Economy Trends: 1975 through 2009; EPA: Washington, DC, USA, 2010. Available online: http://epa.gov/otaq/cert/mpg/fetrends/ 420r09014.pdf (accessed on 10 March 2011). 
14. The fact that ethanol was blended to make up $6 \%$ of car fuel by energy content had little real impact on $\mathrm{CO}_{2}$, since preparing and burning the ethanol released almost as much $\mathrm{CO}_{2}$ as the burning the gasoline replaced.

15. Federal Highway Administration. 2001 National Household Travel Survey; Federal Highway Administration: Washington, DC, USA, 2003.

16. American 10.7 Billion Trips Taken On U.S. Public Transportation In 2008-Highest Level in 52 Years; Ridership Increased as Gas Prices Decline and Jobs Were Lost. Available online: http://apta.com/media/releases/090309_ridership.cfm (accessed on 14 July 2008).

17. U.S. Department of Transportation. Traffic Volume Trends. Available online: http://www.fhwa. dot.gov/ohim/tvtw/tvtpage.cfm (accessed on 10 July 2009).

18. Greene D.L. Energy-Efficiency Improvement Potential of Commercial Aircraft. Annu. Rev. Energy Environ. 1992, 17, 537-573.

19. We assumed 20 passengers average per school bus for years when no data are given by TEDB, close to the average for all the years.

20. Kamakate, F.; Schipper, L. Trends in Truck Freight Energy Use and Carbon Emissions in Selected OECD Countries from 1973 to 2005. Energy Policy 2009, 37, 3743-3751.

21. Ang, B.W. Decomposition analysis for policymaking in energy: Which is the preferred method? Energy Policy 2004, 32, 1131-1139, and references therein.

22. Greszler, A. Heavy Duty Vehicle Fleet Technologies for Reducing Carbon Emissions: An Industry Perspective. In Reducing Climate Impacts in the Transport Sector; Sperling, D., Cannon, J., Eds.; Springer: New York, NY, USA, 2008.

23. Schipper, L.; Marie, C.; Gorham, R. Flexing the Link between Urban Transport and $\mathrm{CO}_{2}$ Emissions. Available online: http://www.iea.org/textbase/nppdf/free/2000/flex2000.pdf (accessed on 10 March 2011).

24. Chester, M. Life-cycle Environmental Inventory of Passenger Transportation in the United States. PhD Thesis, Institute of Transportation Studies, University of California, Berkeley, CA, USA, 2008. Available online: http://www.sustainable-transportation.com/ (accessed on 29 May 2009).

25. Simple to compute, the drawback of these indices is that they do not account for the "cross terms" that arise because two more of these components for any mode may have changed by a great detail. Think of expanding the product $(\mathrm{A}+\operatorname{delta} \mathrm{A}) \times(\mathrm{S}+\operatorname{delta} \mathrm{S}) \times(\mathrm{I}+$ delta $\mathrm{I}) \times(\mathrm{F}+$ delta $\mathrm{F})$ without even taking into account L or V separately [22].

26. Ang, B.W. The LMDI approach to decomposition analysis: A practical guide. Energy Policy 2005, 33, 867-871.

27. These include zero residuals, factor reversibility, time reversibility and log additivity. Ang [21] provides a useful comparison of different methods.

28. Pacala, S.; Socolow. R. Stabilization Wedges: Solving the Climate Problem for the Next 50 Years with Current Technologies. Science 2004, 305, 968-972.

29. Schipper, L.; Scholl, L.; Price, L. Energy Use and Carbon Emissions from Freight in Ten Industrialized Countries: An Analysis of Trends from 1973 to 1992. Transp. Res. Part D Transport Environ. 1996, 2, 57-76. 
30. Greene, D.L.; Bunch, D.S. Potential Design, Implementation, and Benefits of a Feebate Program for New Passenger Vehicles in California: Interim Statement of Research Findings. Available online: http://pubs.its.ucdavis.edu/publication_detail.php?id=1400 (accessed on 10 March 2011).

31. Boutin, X.; Haultfoeuille, X.; Givord, P. The Environmental Effect of Green Taxation: The Case of the French Bonus-Malus. In Proceedings of The 11th CEPR Conference on Applied Industrial Organization, Toulouse, France, 29 May 2010.

32. DeCicco J.; Feng, A. Automakers' Corporate Carbon Burdens, Reframing Public Policy on Automobiles, Oil and Climate. Available online: http://www.edf.org/documents/2220 AutomakersCorporateCarbonBurdens.pdf (accessed on 10 March 2011).

33. Parry, I.; Walls, M.; Harrington, W. Automobiles Externalities and Policies. J. Econ. Lit. 2007, 45, 373-399.

34. Energy Information Administration. Annual Energy Outlook. Available online: http://www.eia. doe.gov/oiaf/aeo/ (accessed on 21 September 2010).

(C) 2011 by the authors; licensee MDPI, Basel, Switzerland. This article is an open access article distributed under the terms and conditions of the Creative Commons Attribution license (http://creativecommons.org/licenses/by/3.0/). 